\title{
A critical review of the vaginal microbiota and its relationship with human papillomavirus
}

\author{
Chaharzad Said Abdallah, Tianmin Xu*, Cong Wang
}

Department of Obstetrics and Gynecology, $2^{\text {nd }}$ Hospital of Jilin University, Changchun, Jilin, China

Received: 03 February 2022

Revised: 18 February 2022

Accepted: 19 February 2022

\author{
*Correspondence: \\ Dr. Tianmin Xu, \\ E-mail: xutianmin@126.com
}

Copyright: (c) the author(s), publisher and licensee Medip Academy. This is an open-access article distributed under the terms of the Creative Commons Attribution Non-Commercial License, which permits unrestricted non-commercial use, distribution, and reproduction in any medium, provided the original work is properly cited.

\begin{abstract}
The study of bacterial 16S rRNA genes is facilitated with the assistance of next-generation sequencing methods (NGS) which allow a thorough investigation of vaginal microbial community makeup to an extent not achievable with regular culture-supported microbiological methods. The human papillomavirus (HPV) triggers cervical intraepithelial neoplasia (CIN), the precursor of cervical malignancy. Vaginal microbiota has a mutualistic symbiotic connection with their host and has a significant influence on health and disease. Surging proof points to a likely connection between the vaginal microbiota and repeated HPV infections. Some vaginal microbial types can be either prophylactic or pathogenic in cancer development of the cervix after repeated HPV infection. In this review, we discussed the composition and structure of the vaginal microbiota as well as the relationship between HPV infection and the vaginal microbiota. We also covered the link between the vaginal microbiome, HPV, and immune response.
\end{abstract}

Keywords: Vaginal microbiota, Human papillomavirus, CIN

\section{INTRODUCTION}

The microbiota has a significant impact on body growth, physiology, immune defense and nutrition. ${ }^{1,2}$ The predominant part of native microbiota exists in an interdependent cooperation with their respective host; however not many are opportunistic bacteria that have the capacity to induce both prolonged infections and critical illnesses. These microbial communities establish the primary line of protection in the event of an infection by competitively preventing the infection of invasive acquired organisms capable of causing diseases. Even though they are of importance not much is understood about the structure and purpose of these communities among distinct people, but particularly, in what way their inherent units collaborate with each other and the host to create an everchanging complex system that acts according to changes in the environment. Major steps are now taken for the purpose of better comprehending the specific function of these communities in health and diseases. ${ }^{3}$ STDs are one of the major widespread infectious diseases globally. The CDC in the United States disclosed that over 20 types of STDs are recorded in nearly 19 million cases yearly. ${ }^{4}$

HPV is among the main causative factors of STDs (sexually transmitted diseases) globally. ${ }^{5}$ Over $200 \mathrm{HPV}$ of distinct genetic constitutions have been detected and mainly arranged into two groups namely high and low risk groups. This classification is established on the basis of the conceivable outcome of suffering from a malignancy. That being the case, the HPV types categorized as high risk are observed in about $99 \%$ of all cervical malignancies. ${ }^{6,7}$ Furthermore, the high risk ones have been stated to occupy a significant part in other cancers namely anal, vulvar, and penile. The scattering of the genotype along with the genetic makeup of each HPV is deemed essential for prophylaxis, prognosis and management of disease. ${ }^{8}$ The 
likelihood of infection from HPV is quite frequent due to the effortless propagation of various types of HPV from person to person through the skin and mucosa. Regardless, most of the infections are at an asymptomatic stage and temporary as they are inhibited by a strong immune system. ${ }^{9}$ Hence, despite the fact that HPV infection occurs frequently over $80 \%$ in sexually active people over their lifetime, the percentage of HPV associated diseases is relatively smaller. ${ }^{10}$ In this review, we discussed the vaginal microbiota (VMB) in conjunction with HPV infection. In addition, we discussed the vaginal microbiome (VM) alongside HPV and immune response. Figure 1 highlights the general plan of this presented review article.

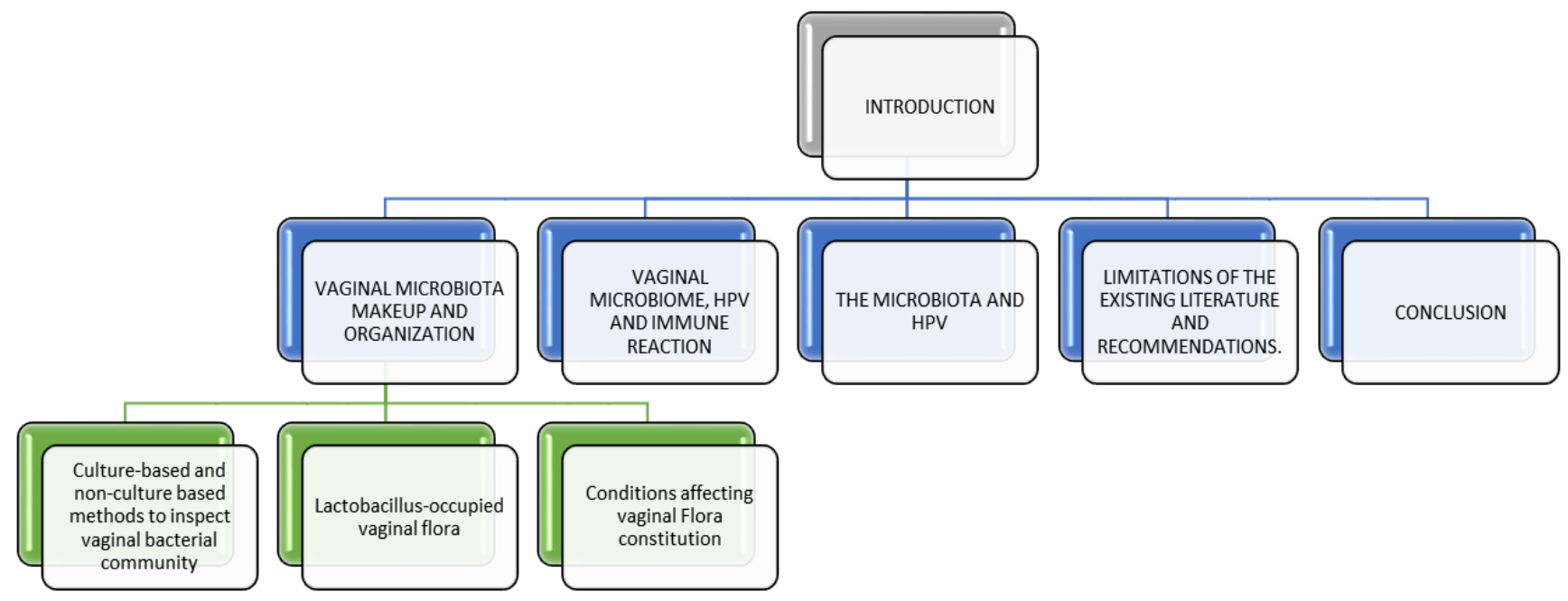

Figure 1: General outline of this present review.

Table 1: Datasets applied to identify the HVMC (human vaginal microbial communities) state types.

\begin{tabular}{|c|c|c|c|c|c|}
\hline Datasets & Cross-sect & group & & & \\
\hline Types & Type I & Type II & Type III & Type IV & Type V \\
\hline Main species & L. cripatus & L. gasseri & L. iners & N/A & L. jensenii \\
\hline Sample size & 105 & 25 & 135 & 108 & 21 \\
\hline
\end{tabular}

Table 2: Datasets utilized to analyze CST (community state types) measurement with distinction of species; owing to a fairly limited sample size, CST-V was not identified.

\begin{tabular}{|c|c|c|c|c|c|c|}
\hline \multirow{3}{*}{ Types } & \multicolumn{5}{|c|}{ Longitudinal group } & \multirow{3}{*}{ Type V } \\
\hline & \multirow{2}{*}{ Type I } & \multirow{2}{*}{ Type II } & \multirow{2}{*}{ Type III } & \multicolumn{2}{|c|}{ Type IV } & \\
\hline & & & & IV-A & IV-B & \\
\hline Dominant species & L. cripatus & L. gasseri & L. iners & N/A & N/A & L. jensenii \\
\hline Sample size & 163 & 57 & 379 & 91 & 247 & 0 \\
\hline
\end{tabular}

\section{VMB makeup and organization}

Ravel designed a cross-sectional study of healthy reproductive-age women and classified the HVMC into five CSTs. ${ }^{11}$ Among them, CSTs I, II, III and V were dominated by Lactobacillus spp. whilst CST IV had no particular prevalent species. The specific species that makeup these CSTs are demonstrated in Table $1 .{ }^{11}$

Later on, Gajer through a longitudinal study further split HVMC CST IV into type CST IV-A and CST IV-B as shown in Table 2 in which CST IV A was made up of small quantities of either L. iners or other Lactobacillus spp., combined with slight amounts of diverse species of strictly anaerobic bacteria and CST IV B was comprised of greater amounts of the genus Atopobium, along with Gardnerella, Mobiluncus and various additional taxa. ${ }^{12}$

In-depth studies of vaginal microbial community utilizing non-culture-based methods have exposed that Lactobacillus spp. were the main vaginal microorganism groups in most women. Although a considerable quantity of asymptomatic individuals had a vaginal microbiota missing considerable amounts of Lactobacillus spp. and 
holds a various range of facultative and strict anaerobic bacteria.

\section{Culture-based and non-culture-based methods to inspect vaginal bacterial community}

Culture of the microbial population has been the main tool used to understand the constitution and metabolic functional capability of native bacterial communities. Consequently, the current knowledge of microbiota-host interaction was insufficient and partial due to most microbial species being culture-resistant in the laboratory. ${ }^{13}$ The restricted facility to culture may be caused by strict, not yet identified, growth conditions including the ideal blend of nutrients, optimal growth temperatures, dissolved-oxygen levels or possibly the requirement to cultivate together with other important microorganisms. ${ }^{14}$

At present, the understanding of microbial variation had tremendously widened owing to the implementation of non-culture-based techniques which were established on the study of $16 \mathrm{~S}$ rRNA gene sequences. ${ }^{15}$ These techniques bypassed the necessity to culture the microorganisms by instantly removing genetic matters from either environmental or biological specimens. The $16 \mathrm{~S}$ rRNA genes were amplified by means of primers capable of annealing to highly conserved areas of the gene; this step was then followed by the detection of existing phylotypes by sequencing and classification. This procedure was a productive mean to broadly identify diverse microbiome. The advancement of next-generation sequencing tools such as the application of massively parallel DNA sequencing of short, offered the advantage to acquire thorough studies of microbial communities, namely the detection of taxa existing in shortage that encompassed the uncommon biospheres. ${ }^{16}$ Non-culture based techniques by means of cross-sectional studies have recognized that numerous types of vaginal CSTs appeared in normal women, with all of these women having a distinctly diverse bacterial species makeup.

\section{Lactobacillus-occupied vaginal flora}

It was well established that bacteria that belonged to the genus Lactobacillus were generally documented as the unique trait of a healthy vagina. ${ }^{17}$ Ever since Lactobacillus spp. were initially detected, through vaginal secretion culture, they were believed to have a critical function in defending the vagina from acquired and likely dangerous microorganisms. ${ }^{18}$ This protection was achieved via the synthesis of lactic acid leading to a low and prophylactic $\mathrm{pH} .{ }^{19}$ On the other hand, lactic acid had been proved to be particularly more active than just acidity at neutralizing infectious agents such as Neisseria gonorrhea. ${ }^{20}$ Furthermore, in the event of gram-negative bacteria infection, lactic acid was believed to intensify the innate immune reaction. ${ }^{21}$ Earlier, L. crispatus was considered to be among the main components of lactobacilli in the vagina. This was later revealed to be inaccurate as a result of implementing non-culture based techniques which revealed that $L$. iners which failed to mature on conventional culture media as the main widespread vaginal bacterial species. ${ }^{22}$ In a 2010 study, Zhou found that the classification of Lactobacillus spp. occupied CSTs considerably fluctuates amid different ethnicities. ${ }^{23}$ The authors noticed that there was an elevated average $\mathrm{pH}$ in Black which was 4.7 and Hispanic which was 5.0 women, compared to Asian (4.4) and White (4.2) women. This study reinforced the theory that the characterization of the vaginal flora composition and structure was greatly influenced by various characteristics of the host. In addition, strains of identical species also displayed genomic disparities that arose in precise physiological and biochemical features.

Prior genomic studies based on comparison have revealed that there was a significant proportion of genetic heterogeneity as well as varied metabolic potential of strongly associated bacterial species or strains of identical species. The majority of the variations arose as large genomic islands or lineage located in particular areas that may take part in the adaptation to the host microenvironment. ${ }^{24}$ Progressive understanding of genetic variation amongst Lactobacillus species could possibly offer additional understanding into their possible functions that may have important inferences to health and diseases. Due to species genomic diversity, it was critical to take notice of the study of $16 \mathrm{~S}$ rRNA gene sequences, that abled to characterize the taxonomy, was unable to determine functional variations without significant assumptions. And thus, trying to deduce behavior of any bacterial community by merely identifying which taxa was present should be made with precaution.

\section{Conditions affecting vaginal flora constitution}

The components of vaginal flora were affected by several aspects. Racial background was a leading innate feature noted to be considerably connected with differences in community makeup, with Caucasian and Asian women exhibiting a considerable larger incidence of Lactobacillus species dominated microbiota, in comparison with Hispanic and Black women. ${ }^{11}$ These variations may be influenced by genes that affected the immunity of the mucosal membrane or metabolic pathways, developing in favoured conditions for specific species and similarly possibly would be caused by the disparity in divergent sanitary habits. It was well known that menstrual sanitary habits were greatly influenced by cultural and social norms. ${ }^{25}$ In fact, a representative COHORT study found that vaginal douching was common in $22 \%$ of the studied sample, which was two times as prevalent in Black women, in comparison with Caucasians. ${ }^{26,27}$ The consistency of the vaginal flora was largely influenced by female hormones. As a matter of fact, under estrogen stimulation, Lactobacillus spp. quickly occupied the vagina after birth even though the vagina was considered initially sterile at birth. Decreased estrogen concentrations 3 to 4 weeks after birth coincided with a decline in vaginal 
Lactobacillus and enhanced species variation with enhancement of strict anaerobe and enteric species, which was preserved until puberty. ${ }^{28}$ Enhanced estrogen and progesterone production prior to menarche promoted decreased vaginal microbiota diversity and comparatively raised Lactobacillus spp. in copious amount. ${ }^{29}$ During the course of the reproductive period, alteration of VMB makeup can be connected to the periodical excretion of estrogen and progesterone during the course of the menstrual cycle. The time period that the concentrations of estrogen and progesterone were most depleted was during menstruation and during this period, the greatest variation and imbalance was noted. ${ }^{30}$ The organization of the vaginal mucosa and its surroundings were greatly influenced by the presence of menstrual blood which led to the reduction of particular species and amplification of others.

The maximal consistency of vaginal microbiota organization throughout the menstrual cycle was seen when the highest concentration of estrogen occurred, afterwards maximal progesterone concentration occurred some days later. ${ }^{12}$ In the wake of menopause, decreased estrogen and ensuing vaginal atrophy were believed to cause Lactobacillus spp. reduction and elevated variety. ${ }^{31}$ Conforming with these results, the postpartum phase in which there was a dramatic decrease in circulating estrogen levels, had been recently presented to be related with a substantial surge in the variety and abundance of the vaginal flora. ${ }^{32} \mathrm{Up}$ to date, the process by which hormones guide vaginal flora makeup was not completely elucidated; however, the abundance of Lactobacillus spp. seemed to be strongly controlled by estrogen led ripening of the vaginal epithelial cells, which subsequently braught about the build-up of glycogen in vaginal epithelia. In addition, the composition of vaginal flora was similarly affected by the widespread usage of synthetic hormones for the aim of contraception. A meta-analysis study that analyzed both the pill and vaginal combined hormonal contraceptives in conjunction with different progesterone-only hormonal contraceptives revealed that the application of hormonal contraception was associated with a 31 and $32 \%$ decrease in persistent and frequent bacterial vaginosis as well as an $18 \%$ lowered risk of incidence. ${ }^{33}$ However, this study indicated that there was no difference in protection between the two studied methods of contraception. Additionally smoking and recent intercourse, along with additional environmental factors were recognized to influence the vaginal microbiota composition. ${ }^{34,35}$ Both these factors were linked with decreased relative quantity of $L$. crispatus and a surge in species diversity. Vaginal douching, especially post-menstruation had been presented to considerably raise the chance of developing bacterial vaginosis and termination of this habit may diminished the risk of $\mathrm{BV}$ (bacterial vaginosis). ${ }^{36,37}$ Similarly, a 2016 study of more than a thousand American women had determined that douching increased the chance of acquiring HPV infection specifically high-risk other hand, the link tying HPV infection to the presence of other forms of $\mathrm{VMB}$, seemed to either be protective or subtypes. ${ }^{38}$ Furthermore, a meta-analysis study established that douching may raise the likelihood of getting CIN and cervical malignancy, which may be caused by the mechanism leading to a surge in bacterial diversity, which was well known to be associated with cervical diseases. ${ }^{39}$

\section{VM, HPV and immune reaction}

There was the likelihood that the stability and makeup of the VM may perform a critical function in characterizing the innate immune defense and the infection tendency as well as play a part in cervical pathology progress. Various studies have shown that bacterial vaginosis-associated microbes and BV impact immunity qualities inside the vagina, consisting of antimicrobial proteins, safe cell populations as well as cytokines/chemokines. ${ }^{40}$ In vitro studies of diverse microbes noted that a few may create proinflammatory reactions. For instance, Atopobium vaginae, a $\mathrm{BV}$ related microscopic organism triggers nuclear factor (NF)- $\kappa \mathrm{B}$, interleukin (IL)-6 and IL-8, tumor necrosis factor (TNF) alpha as well as other proinflammatory factors. ${ }^{41}$ Essentially, the BV related microscopic organisms $G$. vaginalis, S. sanguinegens, $S$. amnii have moreover been detailed to cause comparable $e x$ vivo cytokine and chemokine outline. ${ }^{42}$ Clinical investigations exhibited as well that vaginal microorganism with a prevalence of $\mathrm{BV}$-affiliated organisms and greater diversity promote a comparable inflammatory response with raised IL-8, IL- $1 \alpha$, IL-1 $\beta$, INF- $\gamma$, TNF- $\alpha$ and GM-CSF compared to the typical flora present in women. ${ }^{43}$ Clinical research studies have wellvalidated the impact of the immune system suppression with lower INF $\gamma$-induced protein ten and dissolvable leukocyte protease inhibitor (SLPI) in BV. ${ }^{44,45}$ On the other hand, specific microbes, essentially a prevalence of particular Lactobacillus spp. were related with moderately no inflammatory condition within the cervicovaginal milieu. These proinflammatory mediators contributed to the rise in tissue harm, likely boosting HPV's oncogenic ability. In spite of DNA impairment, expression of E6 and E7 result in the suppression of programmed cell death as well as a surge of cellular growth, leading to an increase in aneuploidy and chromatin anomalies which then lead to the growth of cervical cell abnormality as well as malignancy. As expressed, Lactobacillus spp. Offered some preventive properties; of which numerous may be essential to HPV. Ex vivo investigations confirmed that Lactobacillus spp. utilized cytotoxicity on cervical tumor cells. ${ }^{46-48}$ L. gasseri and L. crispatus were administered to cervical cancer cell lines and human ordinary fibroblastlike cervical (HNCF); results displayed a suppression of cell growth and stimulation of cell death to an extensively larger scale within the cancer cell line. It was noteworthy that Fusobacteria were detected as a potential microbiological marker linked with HPV infection amongst all microbiota, as demonstrated by Lee.${ }^{49}$ On the

predisposing to HPV. Figure 2 depicts the impact of VMB on the progression of an HPV infection. 


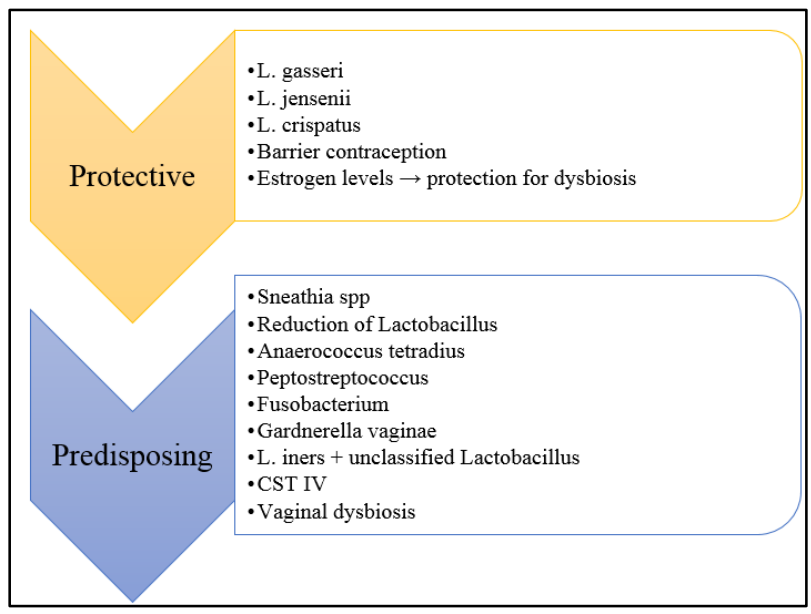

Figure 2: Protective and disadvantaging variables of $\mathrm{VMB}$ in respect to HPV infection.

BV has additionally been revealed to impact immune cell counts inside the mucous membrane of the vagina. However, results were contradictory with proof of inhibition as well as amplification of leukocytes. Contradictory data was potentially a result of most investigations utilizing Nugent score, a subjective scoring system, instead of next-generation sequencing to illustrate microbial imbalance. Without a doubt, there were anticipated genetic and hormonal components that affected host reaction to vaginal pathogens. These included chemokine assortment, cytokine, intrinsic and extrinsic synthetic hormones; these components rendered these dynamics difficult and not completely mastered..$^{50,51}$
Additionally, different types of cervical epithelial cells influenced immune reaction. There was also a positive correlation between considerable areas of cervical columnar epithelium which was normal in pubertal cervixes and increased quantities of proinflammatory cytokines. $^{45,52}$

\section{The microbiota and $\mathrm{HPV}$}

HPV infection was recognized as the initiator of cellular changed that inevitably led to cervical cancer growth. The interruption of the host reaction against tumor antigens included the host immune response and escape mechanisms. Several studies proclaimed that the vaginal microbiome impacted HPV. The event of BV was connected with increased ratios of HPV infection in largely cross-sectional studies, showing that a different microbiome that lacked Lactobacillus may promote HPV perseverance. Additionally, data suggested that HPV persistence was more anticipated to occur in the ones with a changed microbiome. In fact, in a research, patients with determined high risk HPV had a higher predominance of BV $(11 \%)$ in contrast to those who were free of infection. Likewise, Ruler discovered that patients that have acquired BV had a moderate degree of being HPV free. ${ }^{53}$ The main drawback of these studies was that all utilized the flawed Nugent's criteria, which was exceedingly subjective, to quantify BV. Assessments of HPV linked with vaginal microbiota varied from 0.60 to 0.80 . Certain research discovered a tie between vaginal microbiome and HPV infection. These investigations were extremely diverse (Table 3).

Table 3: Correlations between VMB and HPV by nations.

\begin{tabular}{|lllllll|}
\hline $\begin{array}{l}\text { Ref. } \\
\text { No. }\end{array}$ & Year & Country & Study type & $\begin{array}{l}\text { Study } \\
\text { dates }\end{array}$ & $\begin{array}{l}\text { Measure of } \\
\text { association }\end{array}$ & Diagnosis \\
\hline $\mathbf{5 4}$ & 2001 & Costa Rica & Prospective COHORT & $1993-994$ & cOR & Nugent \\
\hline $\mathbf{5 5}$ & 2001 & USA & Prospective COHORT & $1990-2000$ & HR & Amsel \\
\hline $\mathbf{5 6}$ & 2003 & USA & Prospective COHORT & $1990-1997$ & aOR & Amsel \\
\hline $\mathbf{5 7}$ & 2009 & Korea & Cross sectional & $2002-2006$ & cOR & Amsel \\
\hline $\mathbf{5 8}$ & 2009 & Finland & Cross sectional & $2000-2006$ & OR & Clue cells \\
\hline $\mathbf{5 9}$ & 2009 & Italy & Cross sectional & $2007-2009$ & cOR & Amsel \\
\hline $\mathbf{6 0}$ & 2012 & China & Cross sectional & $1998-1999$ & cOR & Amsel \\
\hline $\mathbf{6 1}$ & 2012 & USA & Prospective randomized controlled trial & Amsel \\
\hline $\mathbf{6 2}$ & 2012 & UK & Prospective COHORT & ND-ND & cOR & Nugent \\
\hline $\mathbf{6 3}$ & 2013 & Tanzania & Cross sectional & $2007-2010$ & aOR & Nugent \\
\hline $\mathbf{6 4}$ & 2013 & Tanzania & Prospective randomized controlled trial & $2007-2007$ & cOR & Sequencing \\
\hline $\mathbf{6 5}$ & 2014 & USA & Prospective COHORT & $2008-2009$ & aOR & Clue cells \\
\hline $\mathbf{6 6}$ & 2015 & Brazil & Cross sectional & $2013-2014$ & aOR & Amsel \\
\hline $\mathbf{6 7}$ & 2015 & China & Cross sectional & $2002-2003$ & aRR & Amsel \\
\hline $\mathbf{6 8}$ & 2015 & Thailand & Prospective and retrospective cohort & ND-ND & cOR & Sequencing \\
\hline $\mathbf{6 9}$ & 2015 & UK & Case control & $2006-2015$ & cOR & Sequencing \\
\hline $\mathbf{7 0}$ & 2015 & South Korea & Prospective COHORT & ND-ND & cOR & Clue cells \\
\hline $\mathbf{7 1}$ & 2015 & Brazil & Cross sectional & & & \\
\hline & & & & & &
\end{tabular}


Table 4: The correlation between VMB and HPV varies by age range.

\begin{tabular}{|c|c|c|c|c|c|}
\hline $\begin{array}{l}\text { Ref. } \\
\text { No. }\end{array}$ & Year & $\begin{array}{l}\text { Study } \\
\text { dates }\end{array}$ & Population & $\begin{array}{l}\text { Sample } \\
\text { size }\end{array}$ & $\begin{array}{l}\text { Microbiota } \\
\text { characterization }\end{array}$ \\
\hline \multicolumn{6}{|c|}{ Less than 40 years old } \\
\hline 55 & 2001 & $1990-2000$ & Young women attending family planning clinics & 105 & Amsel \\
\hline 56 & 2003 & 1990-1997 & Freshman female university students & 516 & Amsel \\
\hline 61 & 2012 & $1998-1999$ & Women from general population & 2255 & Amsel \\
\hline 62 & 2012 & 2004-2007 & Female University students & 821 & Nugent \\
\hline 64 & 2013 & $2007-2010$ & Women from schools, colleges & 117 & Nugent \\
\hline 66 & 2015 & $2008-2009$ & Women attending public healthcare facilities & 251 & Clue cells \\
\hline 68 & 2015 & $2002-2003$ & Women attending family planning clinics & 1201 & Amsel \\
\hline \multicolumn{6}{|c|}{ All ages } \\
\hline 69 & 2015 & ND-ND & Women attending colposcopy & 117 & sequencing \\
\hline 70 & 2015 & $2006-2015$ & Women from gynecological oncology clinics & 120 & sequencing \\
\hline 71 & 2015 & ND-ND & Women attending public health centers & 673 & Clue cells \\
\hline 76 & 2008 & $2001-2004$ & Women from the general population & 1055 & Nugent \\
\hline 58 & 2009 & ND-ND & Women from cervical smear screening program & 257 & Clue cells \\
\hline 59 & 2009 & 2000-2006 & women attending clinics for routine gynecological care & 857 & Amsel \\
\hline 60 & 2012 & 2007-2009 & Women from general population & 6185 & Amsel \\
\hline 67 & 2016 & 2013-2014 & Women attending a gynecology clinic & 4290 & Amsel \\
\hline 65 & 2014 & 2005-2007 & Women from general population & 32 & sequencing \\
\hline 63 & 2014 & ND-ND & Women from rural villages & 323 & Nugent \\
\hline
\end{tabular}

Table 4 also included a subgroup investigation of the link between VMB and HPV by age bracket. Lee were one of the initial researchers to utilize NGS to analyze the HPV and the vaginal microbiome by utilizing cervicovaginal specimens of 912 women obtained in the Korean genome epidemiology study. ${ }^{49}$ An overall of 68 participants were examined. The examination of over 40 women that have yet to go through menopause and irrespective of their HPV status detected that the gram-negative bacilli Fusobacteria; specifically, Sneathia spp. can be applied as an indicator of HPV positivity. HPV-infected patients showed greater microbial differences with a lesser amount of Lactobacillus spp. in comparison with HPV-negative ones. At the same time, in HPV-positive patients, there was a reduction of $L$. iners compared to those who were not infected by HPV amongst nine sets of HPV-discordant monozygotic twins. Utilizing non-culture-based method, Gao analyzed $38 \mathrm{HPV}$-affected and $32 \mathrm{HPV}$-negative participants with typical cell study of the cervix. ${ }^{72}$ Their study disclosed that HPV-positive participants had more extensive biological differences by utilizing the ShannonWeiner differences index. While examining particular species, G. vaginalis and L. gasseri were considerably elevated in HPV positive patients. However, these investigations were cross-sectional and thus were incapable of finding out if HPV caused a modification within the VM or if the VM impacted the increased frequency of HPV infection.

Brotman analyzed the time-related association between HPV acquisition and the vaginal microbiome. ${ }^{73}$ Thirty-two sexually active women collected vaginal secretions by way of self-sampling two times a week over 16 weeks. They found that individuals with CSTs III and IV appeared to be more prone to a positive HPV test. On top of analyzing the connection chronic HPV infection and vaginal microbiota share with each other, Brotman also advanced that CST II, predominated by $L$. gasseri and may potentially be related to the fastest clearance of severe HPV infection. ${ }^{73}$ The authors characterized quick clearance as patients that originally had an HPV negative result but changed to positive and then back to negative again. They utilized continuous-time multi-state Markov modelling to assess balanced transition rate ratios. Such a perception may indicate that $L$. gasseri was potentially helpful in preserving cervical health; however, it was noteworthy to observe that only two of the 32 participants had a primarily CST II VM and two more participants with CST III and IV too showed equivalent rapid designs for infection and clearance over the 16-week examination period. Further studies were crucial to support temporal connections between the HPV infection and the vaginal microbiota and to determine if any contrast occured in the shift between high-risk and low-risk HPV subtypes, which was most clinically pertinent. Even though the authors of this study have established that a proportion of VMB may enhance the likelihood of becoming ill from acute and chronic HPV infections, more investigations needed to be executed to address the complex connections between the host, the microbiota and malignant development. Additional research was needed in order to support the temporal connection between vaginal microbiota and HPV infection as well as to find out if there was any discrepancy in highand low-risk HPV interchange. 
Table 5: Features of researches examining the relationship between HPV infection, hrHPV inducing cervical disease and the VM by means of NGS techniques.

\begin{tabular}{|c|c|c|c|c|c|c|}
\hline Study & Reference 75 & Reference 77 & Reference 70 & Reference 69 & Reference 49 & Reference 73 \\
\hline $\begin{array}{l}\text { Results } \\
\text { review }\end{array}$ & $\begin{array}{l}\text { VM diversity } \\
\text { significantly } \\
\text { higher in CIN } \\
\text { than in HPV- } \\
\text { negative } \\
\text { women } \\
\text { L. crispatus } \\
\text { and L. iners } \\
\text { were prevalent } \\
\text { in normal } \\
\text { women } \\
\text { Sneathia spp. } \\
\text { was prevalent } \\
\text { in patients with } \\
\text { CIN; highest } \\
\text { mean } \\
\text { concentrations } \\
\text { of IL-4 and } \\
\text { TGF- } \beta 1 \\
\text { mRNA in } \\
\text { Fusobacterium } \\
\text { spp. VM }\end{array}$ & $\begin{array}{l}\text { L. iners and } \\
\text { undefined } \\
\text { Lactobacillus } \\
\text { spp. were } \\
\text { connected with } \\
\text { upper CIN2+ } \\
\text { rates in } \\
\text { contrast with } \\
\text { various taxa } \\
\text { unclassified } \\
\text { Lactobacillus } \\
\text { spp. } \\
\text { Numerous sub- } \\
\text { genus level } \\
\text { Lactobacillus } \\
\text { were elevated } \\
\text { in patients with } \\
\text { CIN2+ vs } \\
\text { CIN1 }\end{array}$ & $\begin{array}{l}\text { Increased risk } \\
\text { of CIN in the } \\
\text { upper } \\
\text { compared to } \\
\text { the lower } \\
\text { tercile of } \\
\text { dangerous } \\
\text { microbial type } \\
\text { in presence of } \\
\text { hrHPV }\end{array}$ & $\begin{array}{l}\text { CST IV } \\
\text { correlated } \\
\text { with } \\
\text { advancing } \\
\text { disease } \\
\text { progression: } \\
\text { HSIL and } \\
\text { LSIL both } \\
\text { over } 2 \text { times } \\
\text { compared to } \\
\text { normal } \\
\text { There was a } \\
\text { negative } \\
\text { correlation } \\
\text { between CST } \\
\text { I and } \\
\text { advancing } \\
\text { disease } \\
\text { severity }\end{array}$ & $\begin{array}{l}\text { Positive } \\
\text { correlation } \\
\text { between HPV } \\
\text { positive and } \\
\text { increased } \\
\text { diversity and } \\
\text { reduced amount } \\
\text { of } \\
\text { Lactobacillus } \\
\text { spp. in contrast } \\
\text { to HPV- } \\
\text { negative } \\
\text { participants; the } \\
\text { Sneathia spp. } \\
\text { similar to a } \\
\text { microbiological } \\
\text { marker of HPV } \\
\text { positivity }\end{array}$ & $\begin{array}{l}\text { There was an } \\
\text { important } \\
\text { relationship } \\
\text { between CST and } \\
\text { HPV remission } \\
\text { with CST IV-A } \\
\text { having a greater } \\
\text { shift to HPV } \\
\text { positivity in } \\
\text { contrast to CST I } \\
\text { CST II was the } \\
\text { most rapid in } \\
\text { HPV remission. } \\
\text { CST IV-B } \\
\text { involved in the } \\
\text { slowest remission } \\
\text { of HPV }\end{array}$ \\
\hline
\end{tabular}

Numerous other cross-sectional investigations have lately been carried out to classify the VM in patients with cervical lesions. For instance, Mitra examined 169 women including women without cervical lesions as well as those suffering from different lesions namely LSIL, HSIL and ICC. ${ }^{74}$ Their results indicated that the more advanced cervical lesions were correlated with an increasing diversified VM and a relative scarcity of Lactobacillus spp. as well as a gradual surge in CST IV predominance with advancing CIN lesions (Table 3). ${ }^{69}$ Though the control group exhibited a CST IV predominance of $10 \%$ which was in line with earlier findings in healthy lesionfree women, the incidence of CST IV was two, three and four times more increased in low-grade CIN, high-grade $\mathrm{CIN}$ and aggressive cervical malignancy, individually. ${ }^{11}$ Furthermore, Mitra examined a total of 120 Korean women including 70 with CIN to identify biological dynamics between VMB and hrHPV. ${ }^{70}$ They found that patients with CIN had a greater vaginal diversity compared to healthy controls which is in line with Mitra study and Audirac-Chalifour et al. ${ }^{69,75}$

The results of a study examining the VM as well as the vaginal mucosal cytokine profiles of 32 Mexican women validated a number of these aforementioned outcomes despite the fact that a smaller sample size was used. ${ }^{75}$ In fact, Audirac-Chalifour found that in patients with advanced disease, there was a more diverse and a comparatively higher amount of Sneathia spp. as well as members of Fusobacterium spp. (Table 5). ${ }^{75}$ The rise of the latter was correlated with increased of IL-4 readings and TGF- $1 \beta$ mRNA, implying that localized immune response inhibition accelerated HPV immune evasion and disease advancement. Piyathilake have also examined patients that were hrHPV positive with both HSIL and LSIL using the Dirichlet multinomial mixture model to divide samples into four distinct metacommunities, which was unlike the aforementioned CSTs. ${ }^{77}$ However, the authors did not detect an increased diverse VM to be linked to HSIL. This disparity may be caused by racial dissimilarities of the study subjects between studies. Due to the absence of longitudinal data, the above-mentioned studies, can just determine the correlation with disease status instead of causality. ${ }^{69,70,75,77}$ Therefore a good deal of work was required in order to broaden the understanding of the correlation between VM and hrHPV leading to cancer growth. 
Limitations of the existing literature and

The capability to develop an underlying tie between VMB and HPV infection was restricted by the type of studies mostly done in this field, namely cross-sectional studies. This problem was additionally enhanced by the lengthy natural history of the disease, with the time lapse between acute HPV infection and high-grade CIN taking years to decades. Furthermore, several other factors can influence the outcome namely smoking and non-barrier contraception vaginal intercourse which have both been linked with reduction of Lactobacillus spp. ${ }^{34,35}$ Moreover, a significant proportion of existing literature illustrated the VMB in comparatively small sized-samples with lacking or restricted model of a large COHORT of healthy, HPV negative controls for the labelled contrasts. In view of this study design flaw, future studies must therefore be properly planned in order to allow precise analysis of data as well as to guarantee the detection of any alterations in vaginal microbial communities directly related with cervical diseases. These issues can also be resolved by using properly stored samples in historical biobanks to complete longitudinal studies. Nevertheless, drawbacks existed as these biobanks frequently utilized lengthy interval between sampling designs which may fail to illustrated quick alterations in vaginal microbiota composition appearing all through the disease course, at the same time key information like sexual history and smoking may be missing.

It was likely to find an association between the everchanging HPV status and vaginal microbiota variations arising as a consequence of the menstrual cycle to elucidate the function of the VM in the evolving, quick fluctuating pattern of infection. This was demonstrated by an HPV status study carried out by Gajer in which HPV detection reached a peak during the days directly succeeding the time of highest vaginal microbiota diversity (days 7-11). ${ }^{12}$ Though such investigations have been completed in seemingly healthy women, time-based changes of HPV status through limited duration has still not been investigated in women. Additionally, studies addressing the interaction between the microbiota and the host immune system within abstract frameworks focusing on the natural history of HPV infection are also needed. Substitute strategies for the evaluation of VMB and its interplay with the host immune system may as well give helpful approaches to observe HPV infection, continuous and ensuing cervical dysplasia and neoplastic change. For instance, metabolomics were rising as a new technique to study the host-microbe interaction via the examination of functional metabolic modifications connected with disease phenotypes. ${ }^{78}$ Although the VM was the most influential factor that can impact HPV status, the features of the patients are important. In fact, the VM that caused no harm in one patient may be harmful to others. Such disparities in the reaction of patients to identical VM can be influenced by a variation of behavioral, cultural, genetic and several others yet to be known aspects. Thus, the evaluation of these features may possibly guide the suitable understanding of vaginal health and diseases.

\section{CONCLUSION}

The function the vaginal microbiota appears to have regarding the predisposition to HPV infection and its natural history is not yet completely understood. The human vagina carries millions of microorganisms, conventionally acknowledged as the bacterial flora. A growing amount of investigations are gradually untangling the captivating connection between host and microbiota. Because there is few corresponding research in the area, supplementary investigations should be conducted to clarify the interplay between precise microbiota and cervical carcinogenesis affiliated with HPV infection. Taking everything into account, advanced comprehension of the vaginal microbiota may reveal more about chronic HPV infection and correlated diseases and bring forth a desirable therapeutic target.

Funding: No funding sources Conflict of interest: None declared

Ethical approval: Not required

\section{REFERENCES}

1. Cash HL, Whitham CV, Behrendt CL, Hooper LV. Symbiotic bacteria direct expression of an intestinal bactericidal lectin. Science. 2006;313(5790):1126-30.

2. Dethlefsen L, McFall-Ngai M, Relman DA. An ecological and evolutionary perspective on humangmicrobe mutualism and disease. Nature. 2007;449:811-8

3. Peterson J, Garges S, Giovanni M, McInnes P, Wang L, Schloss JA, et al. The NIH Human Microbiome Project. Genome Res. 2009;19(12):2317-23.

4. Trends in HIV and STD-related risk behaviors among high school students-United States, 1991-2007. JAMA. 2008;300(14):1643.

5. Clifford GM, Gallus S, Herrero R, Muñoz N, Snijders PJF, Vaccarella S, et al. Worldwide distribution of human papillomavirus types in cytologically normal women in the International agency for research on cancer HPV prevalence surveys: a pooled analysis. Lancet. 2005;366(9490):991-8.

6. Dols JAM, Reid G, Kort R, Schuren FHJ, Tempelman $\mathrm{H}$, Bontekoe TR, et al. PCR-based identification of eight lactobacillus species and $18 \mathrm{hr}$-HPV genotypes in fixed cervical samples of South African women at risk of HIV and BV. Diagn Cytopathol. 2012:472-7.

7. Clarke MA, Rodriguez AC, Gage JC, Herrero R, Hildesheim A, Wacholder $\mathrm{S}$, et al. A large, population-based study of age-related associations between vaginal $\mathrm{pH}$ and human papillomavirus infection. BMC Infect Dis. 2012;12.

8. Hausen HZ. Papillomaviruses causing cancer: evasion from host-cell control in early events in carcinogenesis. J Natl Cancer Inst. 2000;92(9):690-8. 
9. Bosch FX, deSanjosé S. Chapter 1: Human papillomavirus and cervical cancer--burden and assessment of causality. Journal of the National cancer institute. Monographs. 2003:3-13.

10. Muñoz N, Bosch FX, deSanjosé S, Herrero R, Castellsagué X, Shah KV, et al. Epidemiologic classification of human papillomavirus types associated with cervical cancer. $N$ Engl J Med. 2003;348(6):518-27.

11. Ravel J, Gajer P, Abdo Z, Schneider GM, Koenig SSK, McCulle SL, et al. Vaginal microbiome of reproductive-age women. Proc Natl Acad Sci U S A. 2011;108(1):4680-7.

12. Gajer P, Brotman RM, Bai G, Sakamoto J, Schütte UME, Zhong $\mathrm{X}$, et al. Temporal dynamics of the human vaginal microbiota. Sci Transl Med. 2012;4(132).

13. Bakken LR. Separation and purification of bacteria from soil. Appl Environ Microbiol. 1985;49(6):14827.

14. Amann RI, Ludwig W, Schleifer KH. Phylogenetic identification and in situ detection of individual microbial cells without cultivation. Microbiolog Rev. 1995;59:143-69.

15. Hugenholtz P, Goebel BM, Pace NR. Impact of culture-independent studies on the emerging phylogenetic view of bacterial diversity. J Bacteriol. 1998;180:4765-74.

16. Eckburg PB, Bik EM, Bernstein CN, Purdom E, Dethlefsen L, Sargent M, et al. Microbiology: diversity of the human intestinal microbial flora. Science. 2005;308(5728):1635-8.

17. Sobel JD. Is there a protective role for vaginal flora? Curr Infect Dis Rep. 1999;1(4):379-83.

18. Selle KM, Klaenhammer TR, Russell WM. Lactobacillus: Lactobacillus acidophilus. 2nd ed. In: Encyclopedia of Food Microbiology; 2014: 412-7.

19. Alakomi HL, Skyttä E, Saarela M, Mattila-Sandholm T, Latva-Kala K, Helander IM. Lactic acid permeabilizes gram-negative bacteria by disrupting the outer membrane. Appl Environ Microbiol. 2000;66(5):2001-5.

20. Lai SK, Hida K, Shukair S, Wang YY, Figueiredo A, Cone R, et al. Human immunodeficiency virus type 1 is trapped by acidic but not by neutralized human cervicovaginal mucus. J Virol. 2009;83(21):11196200 .

21. Witkin SS, Alvi S, Bongiovanni AM, Linhares IM, Ledger WJ. Lactic acid stimulates interleukin-23 production by peripheral blood mononuclear cells exposed to bacterial lipopolysaccharide. FEMS Immunol Med Microbiol. 2011;61(2):153-8.

22. Zhou X, Bent SJ, Schneider MG, Davis CC, Islam MR, Forney LJ. Characterization of vaginal microbial communities in adult healthy women using cultivation-independent methods. Microbiology. 2004;150(8):2565-73.

23. Zhou X, Hansmann MA, Davis CC, Suzuki H, Brown CJ, Schütte U, et al. The vaginal bacterial communities of Japanese women resemble those of women in other racial groups. FEMS Immunol Med Microbiol. 2010;58(2):169-81.

24. Beres SB, Sylva GL, Barbian KD, Lei B, Hoff JS, Mammarella ND, et al. Genome sequence of a serotype M3 strain of group A Streptococcus: Phageencoded toxins, the high-virulence phenotype, and clone emergence. Proc Natl Acad Sci U S A. 2002;99(15):10078-83.

25. Water Aid. Fact sheet: Menstrual Hygiene matters. Available at: http://www.wateraid.org/whatwedo/our-approach/res. Accessed on 15 January 2022.

26. Koumans EH, Sternberg M, Bruce C, McQuillan G, Kendrick J, Sutton M, et al. The prevalence of bacterial vaginosis in the United States, 2001-2004; associations with symptoms, sexual behaviors, and reproductive health. Sex Transm Dis. 2007;34(11):864-9.

27. Martino JL, Vermund SH. Vaginal douching: Evidence for risks or benefits to women's health. Epidemiologic Reviews. 2002;24:109-24.

28. Sa CR. The biology of the vagina in the human subject. II: The bacterial flora and secretion of the vagina in relation to glycogen in the vaginal epithelium. J Obs Gynecol Br Emp. 1934;41:208-26.

29. Hickey RJ, Zhou X, Settles ML, Erb J, Malone K, Hansmann MA, et al. Vaginal microbiota of adolescent girls prior to the onset of menarche resemble those of reproductive-age women. MBio. 2015;6(2).

30. Eschenbach DA, Thwin SS, Patton DL, Hooton TM, Stapleton AE, Agnew K, et al. Influence of the normal menstrual cycle on vaginal tissue, discharge, and microflora. Clin Infect Dis. 2000;30(6):901-7.

31. Yang C, Tang D. Patient-specific carotid plaque progression simulation. C Model Eng Sci. 2000;1(2):119-31.

32. MacIntyre DA, Chandiramani M, Lee YS, Kindinger L, Smith A, Angelopoulos N, et al. The vaginal microbiome during pregnancy and the postpartum period in a European population. Sci Rep. 2015;5.

33. Vodstrcil LA, Hocking JS, Law M, Walker S, Tabrizi $\mathrm{SN}$, Fairley CK, et al. Hormonal contraception is associated with a reduced risk of bacterial vaginosis: a systematic review and meta-analysis. PLoS One. 2013;8(9).

34. Brotman RM, He X, Gajer P, Fadrosh D, Sharma E, Mongodin EF, et al. Association between cigarette smoking and the vaginal microbiota: a pilot study. BMC Infect Dis. 2014;14(1).

35. Mändar R, Punab M, Borovkova N, Lapp E, Kiiker R, Korrovits $\mathrm{P}$, et al. Complementary seminovaginal microbiome in couples. Res Microbiol. 2015;166(5):440-7.

36. Schwebke JR, Desmond RA, Oh MK. Predictors of bacterial vaginosis in adolescent women who douche. Sex Transm Dis. 2004;31(7):433-6.

37. Brotman RM, Ghanem KG, Klebanoff MA, Taha TE, Scharfstein DO, Zenilman JM. The effect of vaginal 
douching cessation on bacterial vaginosis: a pilot study. Am J Obstet Gynecol. 2008;198(6):628.

38. Bui TC, Thai TN, Tran LTH, Shete SS, Ramondetta LM, Basen-Engquist KM. Association between vaginal douching and genital human papillomavirus infection among women in the United States. J Infect Dis. 2016;214(9):1370-5.

39. Zliang J, Thomas AG, Leybovich E. Vaginal douching and adverse health effects: a meta-analysis. Am J Public Health. 1997;87(7):1207-11.

40. Torcia MG. Interplay among vaginal microbiome, immune response and sexually transmitted viral infections. Int J Molecul Sci. 2019;20.

41. Verreck FAW, deBoer T, Langenberg DML, Zanden L, Ottenhoff THM. Phenotypic and functional profiling of human proinflammatory type- 1 and antiinflammatory type- 2 macrophages in response to microbial antigens and IFN- $\gamma$ - and CD40L-mediated costimulation. J Leukoc Biol. 2006;79(2):285-93.

42. Persson R, Hitti J, Verhelst R, Vaneechoutte M, Persson R, Hirschi R, et al. The vaginal microflora in relation to gingivitis. BMC Infect Dis. 2009;9.

43. Monaghan KL, Wan ECK. The role of granulocytemacrophage colony-stimulating factor in murine models of multiple sclerosis. Cells. 2020;9(3):611.

44. Moscicki AB, Shi B, Huang H, Barnard E, Li H. Cervical-vaginal microbiome and associated cytokine profiles in a prospective study of HPV 16 acquisition, persistence, and clearance. Front Cell Infect Microbiol. 2020;10.

45. Bokulich NA, Laniewski P, Chase DM, Caporaso JG, Herbst-Kralovetz MM. Integration of multi-omics data improves prediction of cervicovaginal microenvironment in cervical cancer. medRxiv. 2020.

46. Vieira V, Calhelha RC, Barros L, Coutinho JAP, Ferreira ICFR, Ferreira O. Insights on the extraction performance of alkanediols and glycerol: using Juglans regia L. Leaves as a source of bioactive compounds. Molecules. 2020;25(11).

47. Agostini M, Almeida LY, Bastos DC, Ortega RM, Moreira FS, Seguin F, et al. The fatty acid synthase inhibitor orlistat reduces the growth and metastasis of orthotopic tongue oral squamous cell carcinomas. Mol Cancer Ther. 2014;13(3):585-95.

48. Davis MA, Delaney JR, Patel CB, Storgard R, Stupack DG. Nelfinavir is effective against human cervical cancer cells in vivo: a potential treatment modality in resource-limited settings. Drug Des Devel Ther. 2016;10:1837-46.

49. Lee JE, Lee S, Lee H, Song YM, Lee K, Han MJ, et al. Association of the vaginal microbiota with human papillomavirus infection in a Korean Twin COHORT. PLoS One. 2013;8(5).

50. Colbert LE, Medrano AD, Previs RA, Eifel PJ, Jhingran A, Ramondetta LM, et al. Association of changes in vaginal microbiome with oligoclonal $\mathrm{T}$ cell expansion and early response to chemoradiation for cervical cancer. J Clin Oncol. 2018;36(5):8.

51. Drozhdina MB. Vaginal microbiota, immune response and some sexually transmitted infections:
Mechanisms of interaction and regulation of the vaginal ecosystem. Klin Dermatologiya Venerol. 2020;19(6):926-33.

52. Kyrgiou M, Mitra A, Moscicki AB. Does the vaginal microbiota play a role in the development of cervical cancer? Translational Research. 2017;179:168-82.

53. Ruler O, Kiewiet JJS, Boer KR, Lamme B, Gouma DJ, Boermeester MA, et al. Failure of available scoring systems to predict ongoing infection in patients with abdominal sepsis after their initial emergency laparotomy. BMC Surg. 2011;11.

54. Castle PE, Hillier SL, Rabe LK, Hildesheim A, Herrero R, Bratti MC, et al. An association of cervical inflammation with high-grade cervical neoplasia in women infected with oncogenic human papillomavirus (HPV). Cancer Epidemiol Biomarkers Prev. 2001;10(10):1021-7.

55. Moscicki AB, Hills N, Shiboski S, Powell K, Jay N, Hanson E, et al. Risks for incident human papillomavirus infection and low-grade squamous intraepithelial lesion development in young females. J Am Med Assoc. 2001;285(23):2995-3002.

56. Mao C, Hughes JP, Kiviat N, Kuypers J, Lee SK, Adam DE, et al. Clinical findings among young women with genital human papillomavirus infection. Am J Obstet Gynecol. 2003;188(3):677-84.

57. Nam KH, Kim YT, Kim SR, Kim SW, Kim JW, Lee $\mathrm{MK}$, et al. Association between bacterial vaginosis and cervical intraepithelial neoplasia. J Gynecol Oncol. 2009;20(1):39-43.

58. Rahkola P, Mikkola TS, Ylikorkala O, VaisanenTommiska M. Association between high risk papillomavirus DNA and nitric oxide release in the human uterine cervix. Gynecol Oncol. 2009;114(2):323-6.

59. Verteramo R, Pierangeli A, Mancini E, Calzolari E, Bucci M, Osborn J, et al. Human papillomaviruses and genital co-infections in gynaecological outpatients. BMC Infect Dis. 2009;9.

60. Caiyan X, Weiyuan Z, Minghui W, Songwen Z. Prevalence and risk factors of lower genital tract infections among women in Beijing, China. J Obstet Gynaecol Res. 2012;38(1):310-5.

61. Wiley DJ, Masongsong EV, Lu S, Heather LS, Salem B, Giuliano AR, et al. Behavioral and sociodemographic risk factors for serological and DNA evidence of HPV6, 11, 16, 18 infections. Cancer Epidemiol. 2012;36(3).

62. Oakeshott P, Aghaizu A, Reid F, Howell-Jones R, Hay PE, Sadiq ST, et al. Frequency and risk factors for prevalent, incident, and persistent genital carcinogenic human papillomavirus infection in sexually active women: Community based COHORT study. BMJ. 2012;345(7864).

63. Lazenby GB, Taylor PT, Badman BS, McHaki E, Korte JE, Soper DE, et al. An association between trichomonas vaginalis and high-risk human papillomavirus in rural tanzanian women undergoing cervical cancer screening. Clin Ther. 2014;36(1):3845 . 
64. Watson-Jones D, Baisley K, Brown J, Kavishe B, Andreasen A, Changalucha J, et al. High prevalence and incidence of human papillomavirus in a COHORT of healthy young African female subjects. Sex Transm Infect. 2013;89(5):358-65.

65. Brotman RM, Shardell MD, Gajer P, Tracy JK, Zenilman JM, Ravel J, et al. Interplay between the temporal dynamics of the vaginal microbiota and human papillomavirus detection. J Infect Dis. 2014;210(11):1723-33.

66. Caixeta RCA, Ribeiro AA, Segatti KD, Saddi VA, Alves RR, Carneiro MA, et al. Association between the human papillomavirus, bacterial vaginosis and cervicitis and the detection of abnormalities in cervical smears from teenage girls and young women. Diagn Cytopathol. 2015;43(10):780-5.

67. Liu J, Liu W, Liu Y, Zhou X, Zhang Z, Sun Z. Prevalence of microorganisms co-infections in human papillomaviruses infected women in Northern China. Arch Gynecol Obstet. 2016;293(3):595-602.

68. Marks MA, Gupta S, Liaw KL, Tadesse A, Kim E, Phongnarisorn $\mathrm{C}$, et al. Prevalence and correlates of HPV among women attending family-planning clinics in Thailand. BMC Infect Dis. 2015;15(1).

69. Mitra A, MacIntyre DA, Lee YS, Smith A, Marchesi JR, Lehne B, et al. Cervical intraepithelial neoplasia disease progression is associated with increased vaginal microbiome diversity. Sci Rep. 2015;5.

70. Oh HY, Kim BS, Seo SS, Kong JS, Lee JK, Park SY, et al. The association of uterine cervical microbiota with an increased risk for cervical intraepithelial neoplasia in Korea. Clin Microbiol Infect. 2015;21(7):674.

71. Peres AL, Camarotti JRSL, Cartaxo M, Alencar N, Stocco RC, Beçak W, et al. Molecular analysis and conventional cytology: Association between HPV and bacterial vaginosis in the cervical abnormalities of a Brazilian population. Genet Mol Res. 2015;14(3):9497-505.
72. Gao W, Weng J, Gao Y, Chen X. Comparison of the vaginal microbiota diversity of women with and without human papillomavirus infection: a crosssectional study. BMC Infect Dis. 2013;13(1).

73. Brotman RM, Shardell MD, Gajer P, Fadrosh D, Chang K, Silver MI, et al. Association between the vaginal microbiota, menopause status, and signs of vulvovaginal atrophy. Menopause. 2018;25(11):1321-30.

74. Mitra A, MacIntyre DA, Marchesi JR, Lee YS, Bennett PR, Kyrgiou M. The vaginal microbiota, human papillomavirus infection and cervical intraepithelial neoplasia: what do we know and where are we going next? Microbiome. 2016;4.

75. Audirac-Chalifour A, Torres-Poveda K, BahenaRomán M, Téllez-Sosa J, Martínez-Barnetche J, Cortina-Ceballos B, et al. Cervical microbiome and cytokine profile at various stages of cervical cancer: a pilot study. PLoS One. 2016;11(4).

76. Allsworth JE, Lewis VA, Peipert JF. Viral sexually transmitted infections and bacterial vaginosis: 20012004 national health and nutrition examination survey data. Sex Transm Dis. 2008;35(9):791-6.

77. Piyathilake CJ, Ollberding NJ, Kumar R, Macaluso M, Alvarez RD, Morrow CD. Cervical microbiota associated with higher grade cervical intraepithelial neoplasia in women infected with high-risk human papillomaviruses. Cancer Prev Res. 2016;9(5):35766.

78. Chandiramani M, Bennett PR, Brown R, Lee YS, Macintyre DA. Vaginal microbiome-pregnant host interactions determine a significant proportion of preterm labour. Fetal Matern Med Rev. 2014;25(1):73-8.

Cite this article as: Abdallah CS, Xu T, Wang C. A critical review of the vaginal microbiota and its relationship with human papillomavirus. Int J Reprod Contracept Obstet Gynecol 2022;11:986-96. 